\title{
Certification of Credence Goods with Consideration of Consumers' Learning Ability
}

\author{
Xujin $\mathrm{Pu}^{1}{ }^{1} \mathrm{Lu} \mathrm{Lu},{ }^{1}$ and Xiaohua Han ${ }^{2}$ \\ ${ }^{1}$ Jiangnan University, Wuxi 214122, China \\ ${ }^{2}$ Guangdong University of Technology, Guangzhou 510006, China \\ Correspondence should be addressed to Xujin Pu; puyiwei@ustc.edu
}

Received 27 February 2014; Accepted 15 April 2014; Published 8 May 2014

Academic Editor: Efstratios Tzirtzilakis

Copyright (c) 2014 Xujin Pu et al. This is an open access article distributed under the Creative Commons Attribution License, which permits unrestricted use, distribution, and reproduction in any medium, provided the original work is properly cited.

\begin{abstract}
The paper constructs a two-period and an infinitely repeated signaling model for the certification of credence goods, with consideration of the learning ability of consumers. Based on the analysis of the existing conditions of separating equilibrium under different situations, results reveal that the certification cost has a significant influence on the separating equilibrium. The range of certification cost for a separating equilibrium is positively related to the usurp cost and the consumers' learning ability and is negatively related to the difference in the production cost. Compared with that in a two-period model, the range of the certification cost for a separating equilibrium is greater in the infinitely repeated model and is positively related to the discount coefficient.
\end{abstract}

\section{Introduction}

Depending on how consumers evaluate them, goods or services can be classified into three categories: search, experience, and credence goods (Nelson [1]; Darby and Karni [2]). The seller of a good or service knows more about this good or service than the consumer himself. The consumer is frequently not even ex post able to observe the quality of the good or service he received (Giraud-Héraud et al. [3]). Such expert services or goods have been called credence goods. For example, in car repairing industry, according to a joint survey by the Consumer Federation of America, the National Association of Consumer Agency Administrators, and the North American Consumer Protection Investigators, faulty repairs in the auto repair market rank first among the top ten consumer complaints in 2010. In medical service industry, due to the information asymmetry between the patient and the physician, the physician may overtreat his patient, that is, provide and charge for a major treatment although a minor treatment would have been sufficient. In the tourism industry, services suffer to a great extent from information asymmetries because their attributes are more difficult to grasp in advance. Therefore, in the market of credence goods, knowing how to solve information asymmetry is important. Third-party (governmental or nongovernmental) organizations have a key role in intervening in the market and certifying the quality of such goods to signal to consumers their unobservable attributes. According to Dewally and Edertington [4], firms differentiate their high-quality products from low-quality products through four signal strategies: (1) developing high reputation, (2) certification by a thirdparty authority, (3) warranties (for goods), and (4) information disclosure. Based on their empirical investigation of the online comic market, they found that, of the four strategies, certification by a third party sends the strongest signal. Roe and Sheldon [5] analyzed the differences between two different credence goods and studied how different systems of food labeling will influence quality selection and pricing. Etile and Teyssier [6] found that when labels are certified by a third-party, or when consumers can identify ethical brands, a separating equilibrium emerges, in which highand low-quality products are exchanged at different prices. However, the efficiency gains are significant with only thirdparty certification. Besley and Ghatak [7] and Conrad [8] pointed out that a separating equilibrium emerges, in which consumers with a strong preference for social responsibility tend to buy high-quality, high-price products, whereas consumers who pay little attention to social responsibility tend to buy standard, low-price products. 
Quality certification is widely used throughout the world because it can translate the credence attributes into understandable quality signals and improve market efficiency. "AB," "LR," "CCP," "AOC," and other official certifications have been mentioned in the WTO/TRIPS Agreement and are widely recognized by consumers in France (Hocquette et al. [9]). From 1973 onward, the US Food and Drug Administration began to implement the HACCP system of the compulsory certification of enterprises for the production of aquatic products, fruit juice, and other food products (Armstrong [10]). By investigating the willingness of Chinese consumers to pay for quality certification, Ortega et al. [11] found that consumers believe certification could reflect the quality of the product better than brand awareness and pointed out that the third-party certification system by nongovernmental organizations has a positive role in consumer decision making. In recent years, China has promoted the quality certification system of credence goods in reference to the international advanced product standards and technical requirements. For example, by the end of 2012, China has certified a total of 75,887 kinds of pollution-free agricultural products, awarded 1,916 certificates to organic products, and registered 1,001 certificates of origin to agricultural products.

However, some scholars have emphasized that information asymmetry is not necessarily solved by third-party certification as low-quality firms can usurp high-quality firms. Anders et al. [12] found that competition among certification organizations affects the objectivity of the certification process and reduces its effectiveness, particularly because of the increasing number of certification organizations and the reduction of market concentration. An article in the Financial Times that unveils the fraud practices used by Chinese firms has drawn considerable attention. International auditing firms that certify textile suppliers in China with standards, such as the SA 8000, are presumably systematically fooled (Harney [13]).

The studies cited above show that a huge portion of the literature focuses on the importance of quality certification in solving the market failure of credence goods and lacks an indepth inquiry into the mechanism of quality certification in most actual markets. The effectiveness of quality certification and the consumers' response to such certification are rarely considered. A large number of behavioral experiments reveal that people are not completely rational and often make decisions in the frame of bounded rationality (Simon [14], Rubinstein [15], Loch \& Wu [16], and Ariely [17]). Therefore, in this study, we consider and incorporate into the model the consumers' learning ability to analyze the conditions for separating and pooling equilibrium in the market of credence goods.

\section{Model Description}

We propose a signaling model with two key players: producers and consumers. Producers fall under two types: those who produce high-quality products (high-quality producers) and those who produce low-quality products (low-quality producers). Under which type a given producer falls is not observable to any consumer and is therefore private information. High-quality producers prefer to advertise to their consumers the high quality of their products. However, the problem is that low-quality producers have an incentive to pretend that their products are of high quality. If a producer opts for certification, it has to pay an additional cost to the certifier. $c_{h}$ denotes the cost of producing a high-quality product, $c_{l}$ the cost of producing a low-quality product, $c_{e}$ the certification cost, and $c_{t}$ the additional cost of certification for low-quality producers in addition to $c_{e}$. Certification costs, which should be paid only once, are nonrecoverable. We assume without loss of generality that the equilibrium prices of certified and noncertified products are $p_{h}$ and $p_{l}\left(p_{h}>p_{l}\right)$, respectively. The indirect utility of a high-quality product is denoted as $v_{h}$, and the indirect utility of a low-quality product is denoted as $v_{l}$. Furthermore, $p_{l} \in\left[c_{l}, v_{l}\right]$ and $p_{h} \in\left[c_{h}, v_{h}\right]$.

Producers know the quality of their products in advance, but consumers do not. Therefore, high-quality and lowquality products are the same to consumers, and the market prices of these products are the same regardless of their quality. The market price should be lower than the price of high-quality products, and it is realized only when the market for high-quality products is separated from the market for low-quality products.

Consumers are aware of the distinctions between highand low-quality products, but they do not exactly know which producers produce high-quality products and those that produce low-quality products. In the first stage, consumers believe that the certified products are high-quality ones. After consumption, some consumers are able to identify whether the certified products are of high quality or not by consulting with professionals, searching for information online, and reading professional books. However, other consumers still fail to make the distinction accurately. Assume that the learning ability of consumers is $\alpha$, which is the proportion of consumers that can identify the real quality of a given product after consumption in each period. If consumers identify the certificated product as a low-quality product, then they will not want to purchase from the "cheating" producer again in the succeeding periods. Otherwise, they will want to buy it again. We let payoffs for the unit consumer be such that he/she receives the indirect utility of the product that he/she buys minus the price he/she pays for it. The unit producer's net profit is such that the producer receives the price that the consumer pays in each period minus the expense of production in each period.

The rest of this paper is organized as follows. The two-period signaling model is formulated in Section 3. The infinitely repeated signaling modelis played in Section 4, and discussion is provided in Section 5. Finally, we conclude our paper in Section 6.

\section{The Two-Period Signaling Model}

Based on the previous assumptions in the case of the twoperiod signaling model, the profit of the producer and the utility of the consumer are shown in Table 1. 
TABLE 1: Producer and consumer' payoff matrix in the two-period signaling model.

\begin{tabular}{ccccc}
\hline & & & Consumer & \\
\hline \multirow{3}{*}{ Producer } & High-quality products & Certified & $\left(2\left(p_{h}-c_{h}\right)-c_{e}, 2\left(v_{h}-p_{h}\right)\right)$ & Nonpurchasing \\
& & Noncertified & $\left(2\left(p_{l}-c_{h}\right), 2\left(v_{h}-p_{h}\right)\right)$ & $\left(-c_{e}, 0\right)$ \\
& & Certified & $\left(\left(p_{h}-c_{l}\right)-c_{e}-c_{t}+(1-\alpha)\left(p_{h}-c_{l}\right),(2-\alpha)\left(v_{l}-p_{h}\right)\right)$ & $\left(-c_{e}-c_{t}, 0\right)$ \\
& \multirow{4}{*}{ Low-quality products } & Noncertified & $\left(2\left(p_{l}-c_{l}\right), 2\left(v_{l}-p_{l}\right)\right)$ & $(0,0)$ \\
\hline
\end{tabular}

3.1. Separating Equilibrium. Many types of weak sequential equilibrium exist in this model. However, we focus only on the separating equilibrium, in which the high-quality producer opts for certification and the low-quality producer does not opt for certification. This equilibrium type is the most intuitive and likely to occur in most actual markets for two reasons: (1) low-quality producers will find opting for certification costly and (2) producers are more likely to earn higher payoffs with certified products because consumers tend to believe that certified products are of higher quality than noncertified products. To meet the conditions "the payoff the low-quality producer gains while not opting for certification is more than that it gains while opting for certification," that is,

$$
2\left(p_{l}-c_{l}\right) \geq\left(p_{h}-c_{l}\right)-c_{e}-c_{t}+(1-\alpha)\left(p_{h}-c_{l}\right) .
$$

Therefore, we obtain

$$
c_{e} \geq 2\left(p_{h}-p_{l}\right)-\alpha\left(p_{h}-c_{l}\right)-c_{t} .
$$

To meet the conditions "the payoff the low-quality producer gains while not opting for certification is less than that the high-quality producer gains while opting for certification," that is, $2\left(p_{l}-c_{l}\right) \leq 2\left(p_{h}-c_{h}\right)-c_{e}$, the high-quality producer will opt for certification. Therefore, we obtain

$$
c_{e} \leq 2\left(p_{h}-c_{h}\right)-2\left(p_{l}-c_{l}\right) .
$$

We find from (2) and (3) that, in the case of the two-period signaling model, a necessary condition for the separating equilibrium is $\alpha>\left(2\left(c_{h}-c_{l}\right)-c_{t}\right) /\left(p_{h}-c_{l}\right)$. The range of certification costs for the separating equilibrium must be

$$
c_{e} \in\left[2\left(p_{h}-p_{l}\right)-\alpha\left(p_{h}-c_{l}\right)-c_{t}, 2\left(p_{h}-c_{h}\right)-2\left(p_{l}-c_{l}\right)\right] .
$$

Proposition 1. In the case of the two-period signaling model, when the learning ability of consumers $\alpha>\left(2\left(c_{h}-c_{l}\right)-c_{t}\right) /\left(p_{h}-\right.$ $\left.c_{l}\right)$ and the certification costs are in the range of $\left[2\left(p_{h}-p_{l}\right)-\right.$ $\left.\alpha\left(p_{h}-c_{l}\right)-c_{t}, 2\left(p_{h}-c_{h}\right)-2\left(p_{l}-c_{l}\right)\right]$, a separating equilibrium exists.

3.2. Pooling Equilibrium. When $\alpha>\left(2\left(c_{h}-c_{l}\right)-c_{t}\right) /\left(p_{h}-\right.$ $\left.c_{l}\right)$, two types of pooling equilibrium exist in the two-period signaling model. If $c_{e}>2\left(p_{h}-c_{h}\right)-2\left(p_{l}-c_{l}\right)$, the producer, whether high- or low-quality, will not opt for certification. By contrast, if $c_{e}<2\left(p_{h}-p_{l}\right)-\alpha\left(p_{h}-c_{l}\right)-c_{t}$, the producer will opt for certification. When $\alpha \leq\left(2\left(c_{h}-c_{l}\right)-c_{t}\right) /\left(p_{h}-c_{l}\right)$, in other words, when the payoff of the low-quality producer opting for certification gains is lower than that of the highquality producer opting for certification gains, in accordance with the "intuitive criterion," no pooling equilibrium exists, in which the producer, whether high- or low-quality, opts for certification.

Proposition 2. In the case of the two-period signaling model, when one of the following conditions is met, that is, (1) $\alpha \leq$ $\left(2\left(c_{h}-c_{l}\right)-c_{t}\right) /\left(p_{h}-c_{l}\right)$ and $(2) \alpha>\left(2\left(c_{h}-c_{l}\right)-c_{t}\right) /\left(p_{h}-c_{l}\right)$ and $c_{e}<2\left(p_{h}-p_{l}\right)-\alpha\left(p_{h}-c_{l}\right)-c_{t}$, the producer, whether highor low-quality, will opt for certification. When $\alpha>\left(2\left(c_{h}-c_{l}\right)-\right.$ $\left.c_{t}\right) /\left(p_{h}-c_{l}\right)$ and $c_{e} \geq 2\left(p_{h}-p_{l}\right)-\alpha\left(p_{h}-c_{l}\right)-c_{t}$, the producer will not.

Based on the analysis above, the types of equilibrium corresponding to different conditions in the case of the twoperiod signaling model are summarized in Table 2.

\section{The Infinitely Repeated Signaling Model}

In the case of the infinitely repeated signaling model, we assume that the discount rate for both the producer and the consumer is $\delta(0<\delta<1)$. The learning ability of the consumer is also $\alpha$. In the succeeding discussion, we take the net present value of the producer's payoff and the consumers' utility in future periods as the payoff vectors of the different paths of action, as shown in Table 3 .

4.1. Separating Equilibrium. In the case of the infinitely repeated signaling model, to meet the condition "the payoff the low-quality producer gains while not opting for certification is more than that he/she gains while opting for certification," the low-quality producer will not opt for certification. That is, $\left(p_{l}-c_{l}\right) /(1-\delta) \geq\left(\left(p_{h}-c_{l}\right) /(1-\delta(1-\right.$ $\alpha)))-c_{e}-c_{t}$. Therefore, we obtain

$$
c_{e} \geq \frac{p_{h}-c_{l}}{1-\delta(1-\alpha)}-\frac{p_{l}-c_{l}}{1-\delta}-c_{t} .
$$

Similarly, to meet the condition "the payoff the lowquality producer gains while not opting for certification is less than that the high-quality producer gains while opting for certification," that is, $\left(p_{l}-c_{l}\right) /(1-\delta) \leq\left(\left(p_{h}-c_{h}\right) /(1-\delta)\right)-c_{e}$, 
TABLE 2: Equilibrium types in the case of the two-period signaling model.

\begin{tabular}{lr}
\hline Conditions & Equilibrium form \\
\hline$\alpha>\frac{2\left(c_{h}-c_{l}\right)-c_{t}}{p_{h}-c_{l}}$ and $c_{e} \in\left[2\left(p_{h}-p_{l}\right)-\alpha\left(p_{h}-c_{l}\right)-c_{t}, 2\left(p_{h}-c_{h}\right)-2\left(p_{l}-c_{l}\right)\right]$ & Separating equilibrium \\
$\alpha>\frac{2\left(c_{h}-c_{l}\right)-c_{t}}{p_{h}-c_{l}}$ and $c_{e}<2\left(p_{h}-p_{l}\right)-\alpha\left(p_{h}-c_{l}\right)-c_{t}$ & Pooling equilibrium \\
$\alpha>\frac{2\left(c_{h}-c_{l}\right)-c_{t}}{p_{h}-c_{l}}$ and $c_{e}>2\left(p_{h}-c_{h}\right)-2\left(p_{l}-c_{l}\right)$ & Pooling equilibrium \\
$\alpha \leq \frac{2\left(c_{h}-c_{l}\right)-c_{t}}{p_{h}-c_{l}}$ & \\
\end{tabular}

TABLE 3: Payoff matrix of producers and consumers in the case of the infinitely repeated signaling model.

\begin{tabular}{|c|c|c|c|c|}
\hline & & & \multicolumn{2}{|c|}{ Consumer } \\
\hline & & & Purchasing & Nonpurchasing \\
\hline \multirow{4}{*}{ Producer } & High-quality products & Certified & $\left(\frac{p_{h}-c_{h}}{1-\delta}-c_{e}, \frac{v_{h}-p_{h}}{1-\delta}\right)$ & $\left(-c_{e}, 0\right)$ \\
\hline & \multirow{3}{*}{ Low-quality products } & Noncertified & $\left(\frac{p_{h}-c_{h}}{1-\delta}, \frac{v_{h}-p_{h}}{1-\delta}\right)$ & $(0,0)$ \\
\hline & & Certified & $\left(\frac{p_{h}-c_{l}}{1-\delta(1-\alpha)}-c_{e}-c_{t}, \frac{v_{l}-p_{h}}{1-\delta(1-\alpha)}\right)$ & $\left(-c_{e}-c_{t}, 0\right)$ \\
\hline & & Noncertified & $\left(\frac{p_{l}-c_{l}}{1-\delta}, \frac{v_{l}-p_{l}}{1-\delta}\right)$ & $(0,0)$ \\
\hline
\end{tabular}

the high-quality producer will opt for certification. Therefore, we obtain

$$
c_{e} \leq \frac{p_{h}-c_{h}}{1-\delta}-\frac{p_{l}-c_{l}}{1-\delta}
$$

We find from (5) and (6) that, in the case of the infinitely repeated signaling model, a necessary condition of the separating equilibrium is $\alpha>\left((1-\delta)\left(c_{h}-c_{l}-c_{t}\right)+\delta(1-\right.$ $\left.\delta) c_{t}\right) / \delta\left[\left(p_{h}-c_{h}\right)+(1-\delta) c_{t}\right]$. The range of certification costs for the separating equilibrium must be

$$
c_{e} \in\left[\frac{p_{h}-c_{l}}{1-\delta(1-\alpha)}-\frac{p_{l}-c_{l}}{1-\delta}-c_{t}, \frac{p_{h}-c_{h}}{1-\delta}-\frac{p_{l}-c_{l}}{1-\delta}\right] .
$$

Proposition 3. In the case of the infinitely repeated signaling model, when $\alpha>\left((1-\delta)\left(c_{h}-c_{l}-c_{t}\right)+\delta(1-\delta) c_{t}\right) / \delta\left[\left(p_{h}-c_{h}\right)+\right.$ $\left.(1-\delta) c_{t}\right]$ and $c_{e} \in\left[\left(\left(p_{h}-c_{l}\right) /(1-\delta(1-\alpha))\right)-\left(\left(p_{l}-c_{l}\right) /(1-\right.\right.$ $\left.\delta))-c_{t},\left(\left(p_{h}-c_{h}\right) /(1-\delta)\right)-\left(\left(p_{l}-c_{l}\right) /(1-\delta)\right)\right]$, a separating equilibrium exists.

4.2. Pooling Equilibrium. When $\alpha>\left((1-\delta)\left(c_{h}-c_{l}-c_{t}\right)+\right.$ $\left.\delta(1-\delta) c_{t}\right) / \delta\left[\left(p_{h}-c_{h}\right)+(1-\delta) c_{t}\right]$, two types of pooling equilibrium exist in the infinitely repeated signaling model. If $c_{e}>\left(\left(p_{h}-c_{h}\right) /(1-\delta)\right)-\left(\left(p_{l}-c_{l}\right) /(1-\delta)\right)$, the producer, whether high- or low-quality, will not opt for certification. By contrast, if $c_{e}<\left(\left(p_{h}-c_{l}\right) /(1-\delta(1-\alpha))\right)-\left(\left(p_{l}-c_{l}\right) /(1-\delta)\right)-c_{t}$, the producer will opt for certification. When $\alpha \leq\left((1-\delta)\left(c_{h}-\right.\right.$ $\left.\left.c_{l}-c_{t}\right)+\delta(1-\delta) c_{t}\right) / \delta\left[\left(p_{h}-c_{h}\right)+(1-\delta) c_{t}\right]$, that is, when the payoff gained by the low-quality producer opting for certification is lower than that gained by a high-quality producer opting for certification, in accordance with the "intuitive criterion," there will not exist any pooling equilibrium, in which the producer, whether high- or low-quality, opts for certification.

Proposition 4. In the case of the infinitely repeated signaling model, when one of the following conditions is met, that is, (1) $\alpha \leq\left((1-\delta)\left(c_{h}-c_{l}-c_{t}\right)+\delta(1-\delta) c_{t}\right) / \delta\left[\left(p_{h}-c_{h}\right)+(1-\delta) c_{t}\right]$ and $(2) \alpha>\left((1-\delta)\left(c_{h}-c_{l}-c_{t}\right)+\delta(1-\delta) c_{t}\right) / \delta\left[\left(p_{h}-c_{h}\right)+(1-\delta) c_{t}\right]$ and $c_{e}<\left(\left(p_{h}-c_{l}\right) /(1-\delta(1-\alpha))\right)-\left(\left(p_{l}-c_{l}\right) /(1-\delta)\right)-c_{t}$, the producer, regardless of its quality, will opt for certification. When $\alpha>\left((1-\delta)\left(c_{h}-c_{l}-c_{t}\right)+\delta(1-\delta) c_{t}\right) / \delta\left[\left(p_{h}-c_{h}\right)+(1-\delta) c_{t}\right]$ and $c_{e}>\left(\left(p_{h}-c_{h}\right) /(1-\delta)\right)-\left(\left(p_{l}-c_{l}\right) /(1-\delta)\right)$, the producer, regardless of its quality, will not.

Based on the analysis above, the forms of equilibrium that correspond to different conditions in the infinitely repeated signaling model are summarized in Table 4.

\section{Discussion}

In this section, we will discuss how changes of different parameters influence the certification cost and how different the ranges of certification cost are in the two-period and infinitely repeated signaling models.

Let $c_{e}{ }^{\mathrm{TL}}$ denote the lower limit of the certification cost in the two-period signaling model, $c_{e}{ }^{\mathrm{TU}}$ denote the upper limit of the certification cost in the two-period signaling model, $c_{e}{ }^{\text {IL }}$ denote the lower limit of the certification cost in the infinitely repeated signaling model, and $c_{e}{ }^{\mathrm{IU}}$ denote 
TABLE 4: Equilibrium forms corresponding to different conditions in the case of the infinitely repeated signaling model.

\begin{tabular}{lr}
\hline Conditions & Equilibrium forms \\
$\alpha>\frac{(1-\delta)\left(c_{h}-c_{l}-c_{t}\right)+\delta(1-\delta) c_{t}}{\delta\left[\left(p_{h}-c_{h}\right)+(1-\delta) c_{t}\right]}$ and $c_{e} \in\left[\frac{p_{h}-c_{l}}{1-\delta(1-\alpha)}-\frac{p_{l}-c_{l}}{1-\delta}-c_{t}, \frac{p_{h}-c_{h}}{1-\delta}-\frac{p_{l}-c_{l}}{1-\delta}\right]$ & Separating equilibrium \\
$\alpha>\frac{(1-\delta)\left(c_{h}-c_{l}-c_{t}\right)+\delta(1-\delta) c_{t}}{\delta\left[\left(p_{h}-c_{h}\right)+(1-\delta) c_{t}\right]}$ and $c_{e}<\frac{p_{h}-c_{l}}{1-\delta(1-\alpha)}-\frac{p_{l}-c_{l}}{1-\delta}-c_{t}$ & Pooling equilibrium \\
$\alpha>\frac{(1-\delta)\left(c_{h}-c_{l}-c_{t}\right)+\delta(1-\delta) c_{t}}{\delta\left[\left(p_{h}-c_{h}\right)+(1-\delta) c_{t}\right]}$ and $c_{e}>\frac{p_{h}-c_{h}}{1-\delta}-\frac{p_{l}-c_{l}}{1-\delta}$ & Pooling equilibrium \\
$\alpha \leq \frac{(1-\delta)\left(c_{h}-c_{l}-c_{t}\right)+\delta(1-\delta) c_{t}}{\delta\left[\left(p_{h}-c_{h}\right)+(1-\delta) c_{t}\right]}$ & Pooling equilibrium
\end{tabular}

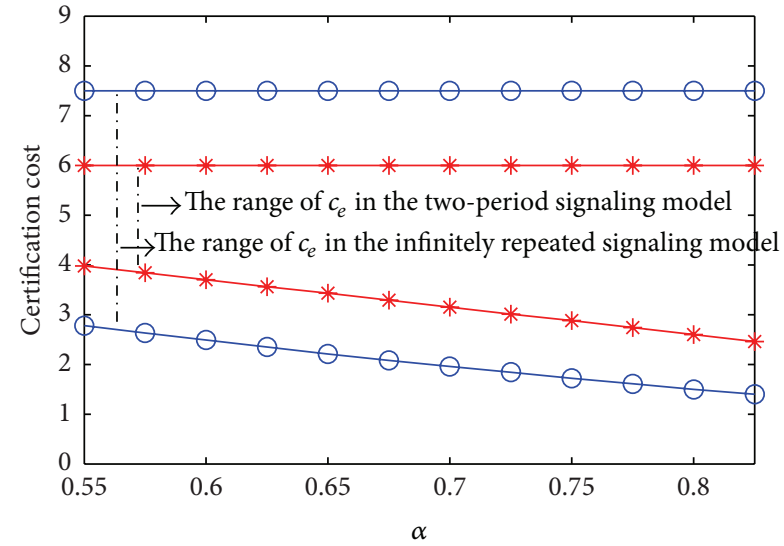

FIGURE 1: Effect of $\alpha$ on the range of $c_{e}$.

the upper limit of the certification cost in the infinitely repeated signaling model.

5.1. Effect of $\alpha$ on the Range of $c_{e}$ When a Separating Equilibrium Exists. Firstly, we analyze the monotonicity of the certification cost and get the partial derivative of $\alpha$,

$$
\begin{array}{cl}
\frac{\partial c_{e}{ }^{\mathrm{TL}}}{\partial \alpha}=-\left(p_{h}-c_{l}\right)<0 ; & \frac{\partial c_{e}^{\mathrm{TU}}}{\partial \alpha}=0, \\
\frac{\partial c_{e}{ }^{\mathrm{IL}}}{\partial \alpha}=-\frac{\delta\left(p_{h}-c_{l}\right)}{[1-\delta(1-\alpha)]^{2}}<0 ; & \frac{\partial c_{e}{ }^{\mathrm{IL}}}{\partial \alpha}=0 .
\end{array}
$$

Then we draw Figure 1 to show the ranges of $c_{e}$ in the twoperiod and infinitely repeated signaling models. (When $p_{h}=$ $10, p_{l}=6, c_{h}=5.5, c_{l}=4.5, c_{t}=1$, and $\delta=0.6$, with $\alpha$ from 0.550 to 0.825 at a step of 0.025 .)

From the monotonicity analysis and Figure 1 above, we obtain Proposition 5.

Proposition 5. In the two-period and infinitely repeated signaling models, ceteris paribus, the greater the consumers' learning ability is, the bigger the range of the certification cost for a separating equilibrium is.

Proposition 5 means that, after each stage of purchasing, the proportion of consumers who can exactly identify the true quality of the products increases. Even when the certification cost is very low, the producer has to bear the loss of consumers

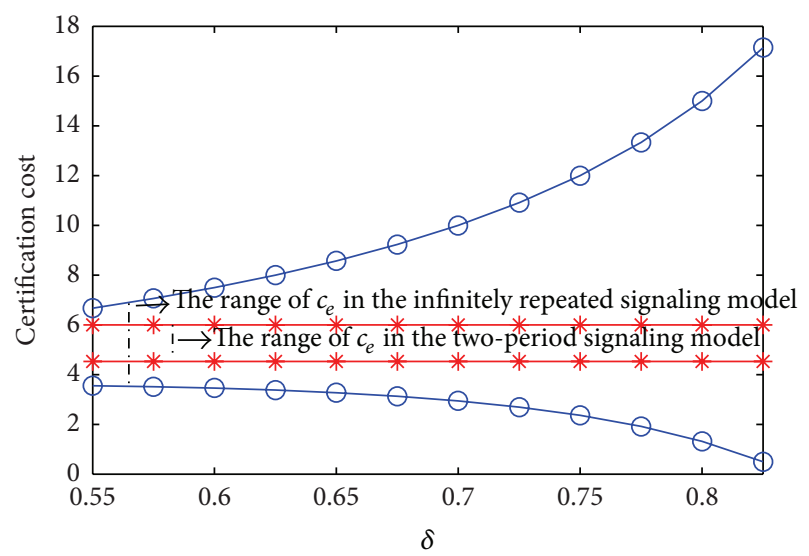

FIGURE 2: Effect of $\delta$ on the range of $c_{e}$.

because the probability of being identified increases. Rational producers will not opt for certification, so that the range of the certification cost for a separating equilibrium becomes greater.

5.2. Effect of $\delta$ on the Range of $c_{e}$ When a Separating Equilibrium Exists. Firstly, we analyze the monotonicity of the certification cost and get the partial derivative of $\delta$,

$$
\begin{gathered}
\frac{\partial c_{e}^{\mathrm{TL}}}{\partial \delta}=0 ; \quad \frac{\partial c_{e}^{\mathrm{TU}}}{\partial \delta}=0, \\
\frac{\partial c_{e}^{\mathrm{IL}}}{\partial \delta}=\frac{(1-\alpha)\left(p_{h}-c_{l}\right)}{[1-\delta(1-\alpha)]^{2}}+\frac{p_{l}-c_{l}}{(1-\delta)^{2}}>0 ; \\
\frac{\partial c_{e}{ }^{\mathrm{IU}}}{\partial \delta}=\frac{-\left(p_{h}-c_{h}\right)+\left(p_{l}-c_{l}\right)}{(1-\delta)^{2}}<0 .
\end{gathered}
$$

Then we draw Figure 2 to show the ranges of $c_{e}$ in the twoperiod and infinitely repeated signaling models. (When $p_{h}=$ $10, p_{l}=6, c_{h}=5.5, c_{l}=4.5, c_{t}=1$, and $\alpha=0.45, \delta$ from 0.550 to 0.825 with the step of 0.025 .)

From the monotonicity analysis and Figure 2, we obtain Proposition 6.

Proposition 6. In the infinitely repeated signaling model, ceteris paribus, the higher the discount rate, the greater 


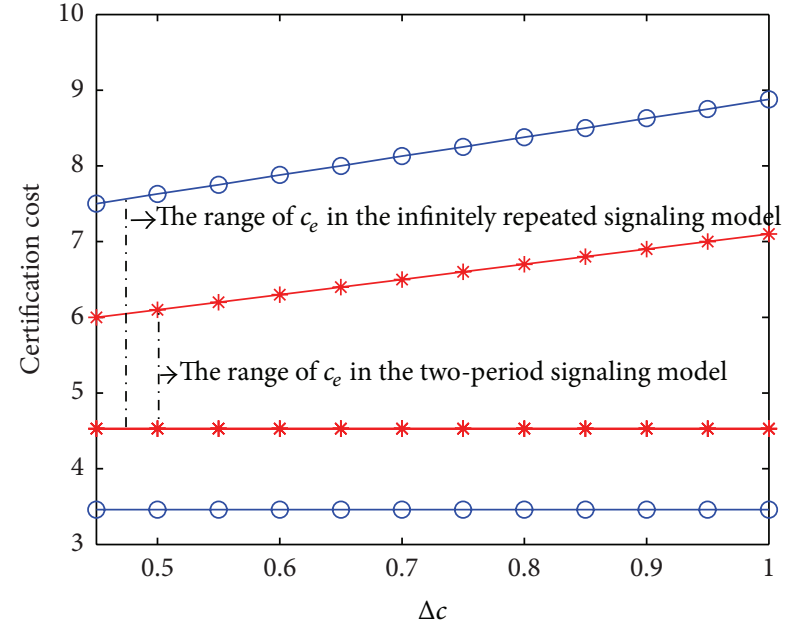

Figure 3: Effect of $\Delta c$ on the range of $c_{e}$.

the range of the certification cost to achieve the separating equilibrium.

Proposition 6 means that the higher the discount rate is, the more attention the producer pays to long-term earnings. Although the certification cost is relatively higher, the highquality producer is willing to opt for certification. However, the low-quality producer gains only short-term earnings by certification. Therefore, certification is not worthwhile because of the loss of consumers.

5.3. Effect of the Cost Difference $\Delta c$ on the Range of Certification Cost $c_{e}$ When a Separating Equilibrium Exists. Assume that $c_{l}$ is constant, so we can just discuss the effect of $c_{h}$ on the range of certification $\operatorname{cost} c_{e}$ when a separating equilibrium exists. Firstly, we analyze the monotonicity of the certification cost and get the partial derivative of $c_{h}$,

$$
\begin{gathered}
\frac{\partial c_{e}^{\mathrm{TL}}}{\partial c_{h}}=0 ; \quad \frac{\partial c_{e}^{\mathrm{TU}}}{\partial c_{h}}=-2<0 \\
\frac{\partial c_{e}^{\mathrm{IL}}}{\partial c_{h}}=0 ; \quad \frac{\partial c_{e}{ }^{\mathrm{IU}}}{\partial c_{h}}=-\frac{1}{1-\delta}<0 .
\end{gathered}
$$

Then we draw Figure 3 to show the ranges of $c_{e}$ in the twoperiod and infinitely repeated signaling models. (When $p_{h}=$ $10, p_{l}=6, c_{l}=4.5, c_{t}=1, \alpha=0.45, \delta=0.6$, and the cost of high-quality products $c_{h}$ is from 5.50 to 4.95 at a step of 0.05 .)

From the monotonicity analysis and Figure 3, we obtain Proposition 7.

Proposition 7. In the two-period and infinitely repeated signaling models, ceteris paribus, the smaller the cost difference between a high-quality product and a low-quality product, the greater the range of the certification cost for a separating equilibrium.

Proposition 7 means that the smaller the cost difference between a high-quality product and a low-quality product is, the more profit the producer gains by producing high-quality products and opting for certification.

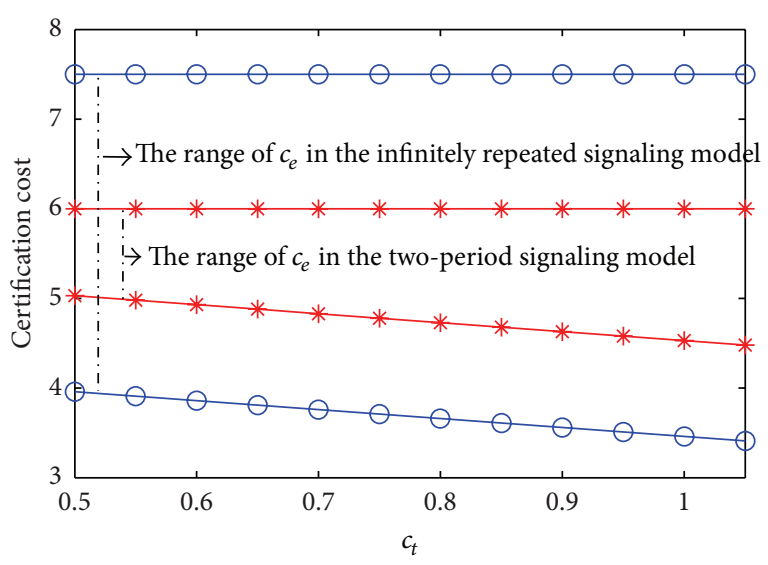

FIGURE 4: Effect of $c_{t}$ on the range of $c_{e}$.

5.4. Effect of $c_{t}$ on the Range of $c_{e}$ When a Separating Equilibrium Exists. Firstly, we analyze the monotonicity of the certification cost and get the partial derivative of $c_{t}$,

$$
\begin{array}{ll}
\frac{\partial c_{e}^{\mathrm{TL}}}{\partial c_{t}}=-1<0 ; & \frac{\partial c_{e}^{\mathrm{TU}}}{\partial c_{t}}=0, \\
\frac{\partial c_{e}^{\mathrm{IL}}}{\partial c_{t}}=-1<0 ; & \frac{\partial c_{e}^{\mathrm{IU}}}{\partial c_{t}}=0 .
\end{array}
$$

Then we draw Figure 4 to show the ranges of $c_{e}$ in the twoperiod and infinitely repeated signaling models. (When $p_{h}=$ $10, p_{l}=6, c_{h}=5.5, c_{l}=4.5, \alpha=0.45, \delta=0.6$, and $c_{t}$ is 0.50 to 1.05 at a step of 0.05 .)

From the monotonicity analysis and Figure 4, we obtain Proposition 8.

Proposition 8. In the two-period and infinitely repeated signaling models, ceteris paribus, the higher the usurp cost, the greater the range of the certification cost for a separating equilibrium.

Proposition 8 means that, considering the loss resulting from being identified exactly, the higher the usurp cost, the lower the incentive for a rational producer to opt for certification.

From Propositions 5 to 8, we obtain Proposition 9.

Proposition 9. Ceteris paribus, when a separating equilibrium exists, the range of the certification cost in the infinitely repeated signaling model is greater than that in the two-period signaling model.

Proposition 9 means that, in the infinitely repeated models of the producer and consumers, the possibility of the producers' usurp being identified exactly is greatly improved. Considering the long-term benefits, producers prefer to opt for certification only for high-quality products and noncertification for lowquality products. 


\section{Conclusion}

In this paper, we focused on certification as a signaling device for the quality of credence goods and analyzed a market in which the producer's quality choice is not observable. We found that certification costs have a significant influence on the existence of a "separating equilibrium," in which only the high-quality producer opts for certification.

We proposed a two-period model and an infinitely repeated signaling model in considering the consumers' learning ability and compared the conditions of the separating and pooling equilibrium in the two signaling models. Our main result implies that we can improve the effectiveness of the certification of credence goods by enhancing consumers' learning ability, guiding producers in long-term operations, increasing the usurp costs of low-quality products, and reducing the costs of high-quality products.

\section{Conflict of Interests}

The authors declare that there is no conflict of interests regarding the publication of this paper.

\section{Acknowledgments}

The authors wish to express their sincerest thanks to the editors and anonymous referees for their constructive comments and suggestions on this paper. This work was supported by the National Natural Science Foundation of China (71371086, 71101032)

\section{References}

[1] P. Nelson, "Information and consumer behavior," Journal of Political Economy, vol. 78, no. 2, pp. 311-329, 1970.

[2] M. R. Darby and E. Karni, "Free competition and the optimal amount of fraud," Journal of Law and Economics, vol. 16, no. 1, pp. 67-88, 1973.

[3] É. Giraud-Héraud, L. Rouached, and L.-G. Soler, "Private labels and public quality standards: how can consumer trust be restored after the mad cow crisis?" Quantitative Marketing and Economics, vol. 4, no. 1, pp. 31-55, 2006.

[4] M. Dewally and L. Ederington, "A comparison of reputation, certification, warranties, and disclosure as remedies for information asymmetries: lessons from the on-line comic book," 2002, http://papers.ssrn.com/sol3/papers.cfm?abstract_ id $=351261$.

[5] B. Roe and I. Sheldon, "Credence good labeling: the efficiency and distributional implications of several policy approaches," American Journal of Agricultural Economics, vol. 89, no. 4, pp. 1020-1033, 2007.

[6] F. Etile and S. Teyssier, "Signaling corporate social responsibility: testing third-party certification versus self-regulation in the lab," 2012, https://www.gate.cnrs.fr/IMG/pdf/Teyssier_2012.pdf.

[7] T. Besley and M. Ghatak, "Retailing public goods: the economics of corporate social responsibility," Journal of Public Economics, vol. 91, no. 9, pp. 1645-1663, 2007.

[8] K. Conrad, "Price competition and product differentiation when consumers care for the environment," Environmental and Resource Economics, vol. 31, no. 1, pp. 1-19, 2005.
[9] J.-F. Hocquette, A. Jacquet, G. Giraud et al., "Quality of food products and consumer attitudes in France," in Consumer Attitudes to Food Quality Products, vol. 133 of EAAP_European Federation of Animal Science, pp. 67-82, Wageningen Academic, Wageningen, The Netherlands, 2013.

[10] D. J. Armstrong, "Food chemistry and U.S. food regulations," Journal of Agricultural and Food Chemistry, vol. 57, no. 18, pp. 8180-8186, 2009.

[11] D. Ortega, H. Wang, N. Olynk, L. Wu, and J. Bai, "Chinese consumers' demand for food safety attributes:a push for government and industry regulation," American Journal of Agricultural Economics, vol. 94, no. 2, pp. 489-495, 2012.

[12] S. Anders, D. M. Souza-Monteiro, and E. Rouviere, "Objectiveness in the market for third-party certification: does market structure matter?" in Proceedings of the 105th EAAE Seminar of International Marketing and International Trade of Quality Food Products, pp. 8-10, Bologna, Italy, March 2007.

[13] A. Harney, "Laying a false trail: how chinese factories dupe western buyers and cheat their staff," Financial Times, no. 22, 2005.

[14] H. A. Simon, "A behavioral model of rational choice," The Quarterly Journal of Economics, vol. 69, no. 1, pp. 99-118, 1955.

[15] A. Rubinstein, Modeling Bounded Rationality, The MIT Press, Cambridge, Mass, USA, 1998.

[16] C. H. Loch and Y. Wu, Behavioral Operations Management, Now Publishers, Boston, Mass, USA, 2007.

[17] D. Ariely, "The end of rational economics," Harvard Business Review, vol. 87, no. 7, 2009. 


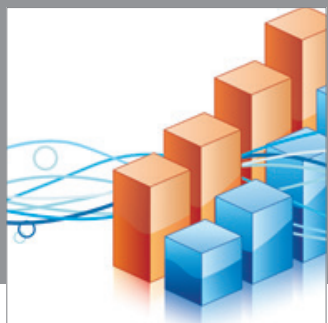

Advances in

Operations Research

mansans

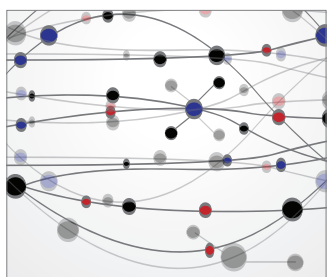

The Scientific World Journal
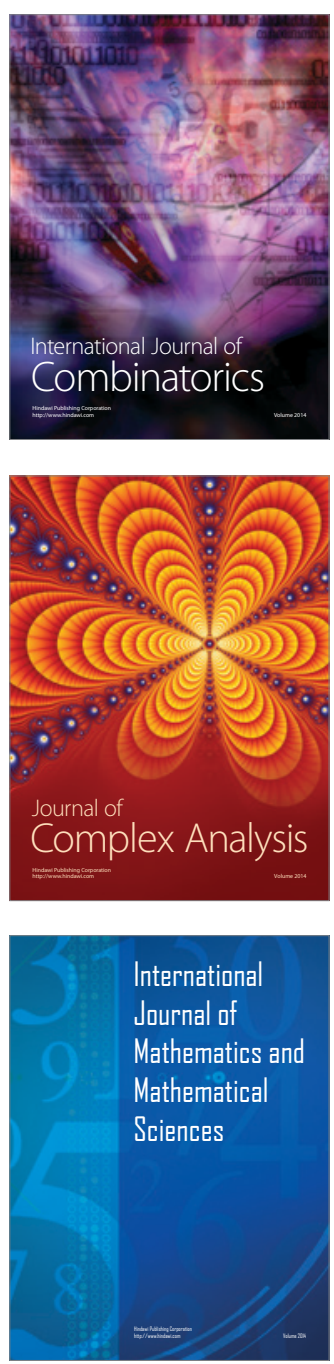
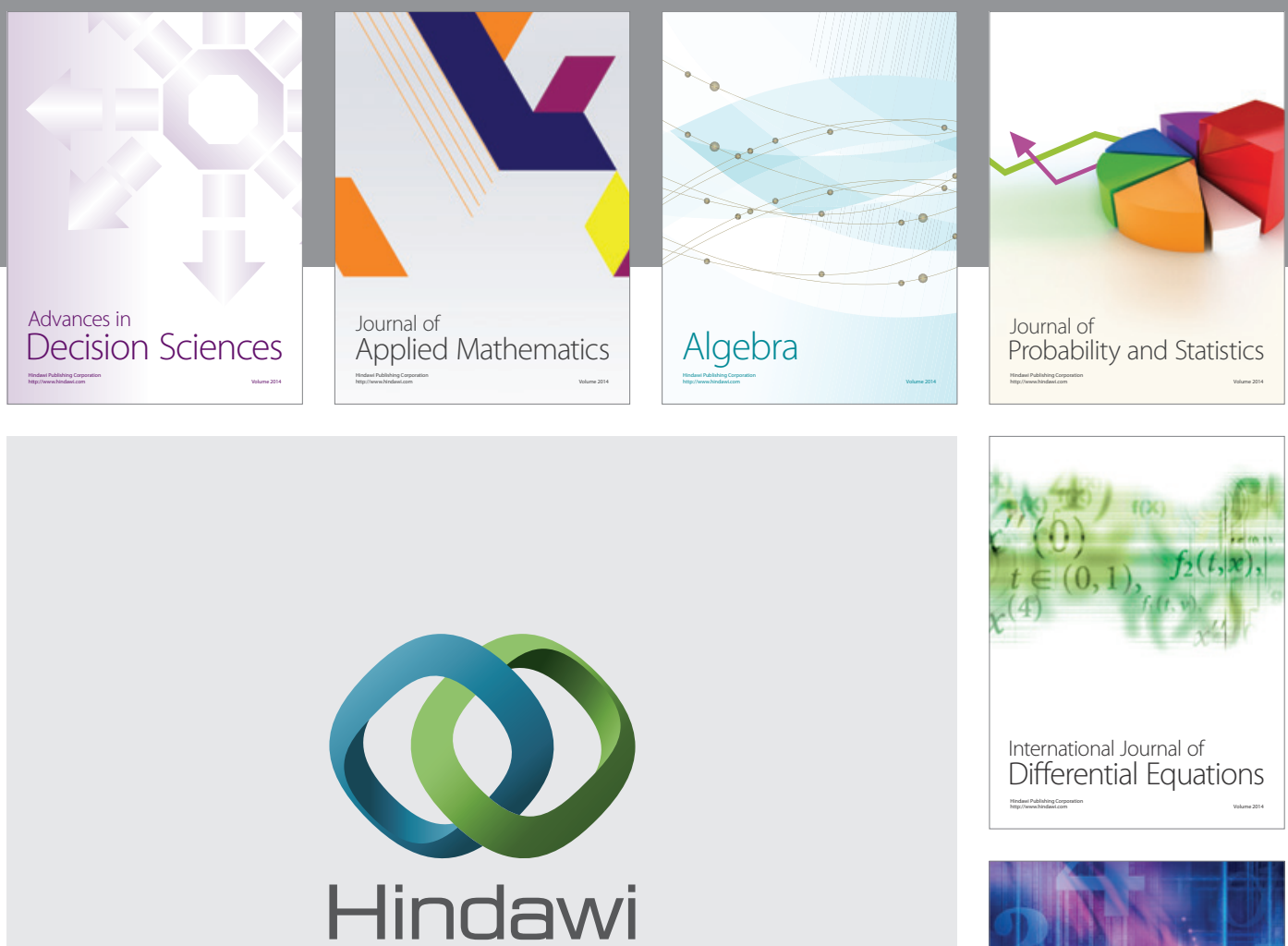

Submit your manuscripts at http://www.hindawi.com
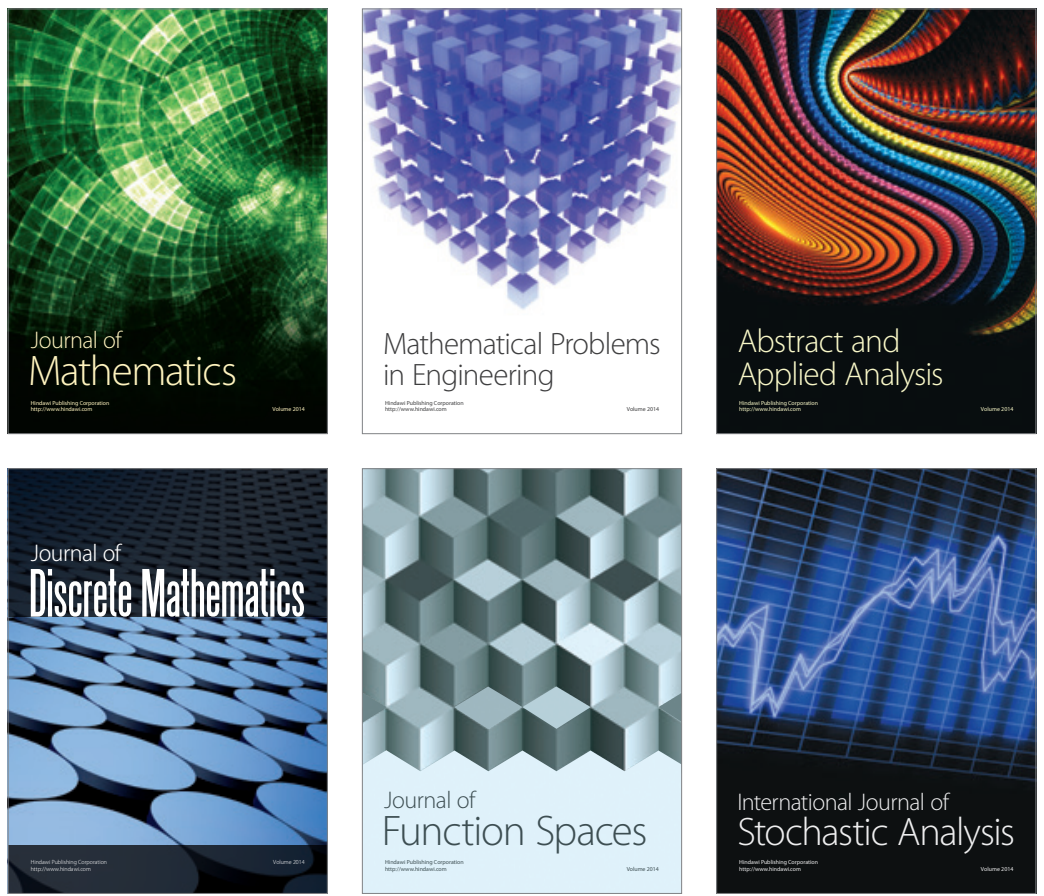

Journal of

Function Spaces

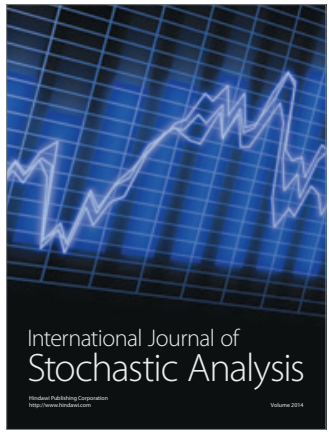

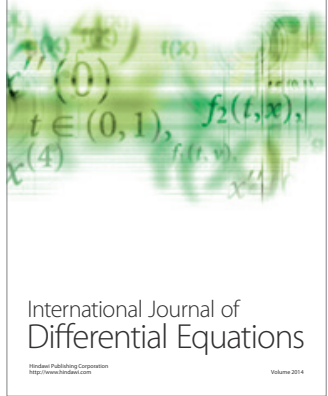
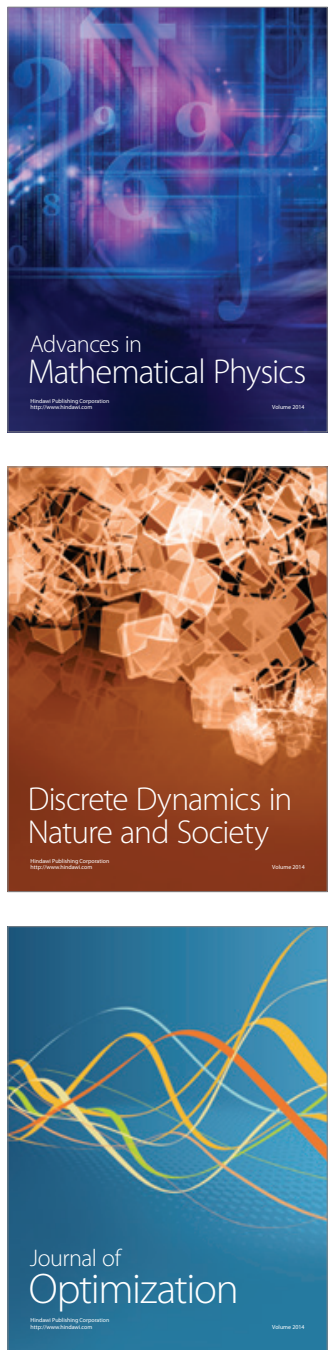